\title{
VIII \\ O USO DO LIVRO DIDÁTICO DE HISTÓRIA NOS ANOS INICIAIS DO ENSINO FUNDAMENTAL NA ESCOLA PÚBLICA: UMA ANÁLISE NO MUNICÍPIO DE ITAIPULÂNDIA*
}

Janete Liane Boehm Lutke

\section{INTRODUÇÃO}

Inúmeros são os questionamentos em relação a função da educação e da escola. Pode-se dizer que a instituição escolar é um campo que está sob imensa disputa, quer pela função que ela realmente exerce no tipo de sociedade que vem se configurando, quer pelas funções que os homens pensam que ela exerce ou poderia exercer. Em meio a essa disputa, é possível constatar visões ideológicas que demonstram a concepção que se tem quanto a relação entre educação e escola e para qual finalidade está sujeita.

Concebendo que a escola está inserida na sociedade, sendo, dessa forma, a educação determinada por ela e também determinante, se faz necessário adotar uma teoria que tenha como prioridade o trabalho dos conteúdos, num processo educativo metódico e intencional. Dessa forma, haverá possibilidade de uma educação com finalidade para a transformação social que, só será possível por meio de uma pedagogia revolucionária.

A Pedagogia Histórico-crítica apresenta-se como sendo uma teoria que supera a clássica contraposição entre as pedagogias da essência e da existência, a partir de uma concepção que procura firmar-se sobre uma base histórica e historicizante.

Ao analisarmos o processo histórico de elaboração da PHC, observamos que, por tratar-se de uma concepção contra-hegemônica, inexistem condições para seu desenvolvimento na sociedade capitalista bem como sua efetivação visando a formação de indivíduos capazes de pensar, agir, sentir e avaliar de forma teleológica.

Segundo Saviani (2013), a escola é uma instituição cujo papel consiste na transmissão do saber elaborado, num movimento dialético, em que acontece a passagem do saber espontâneo ao saber sistematizado. 
Entendemos que os pressupostos da Pedagogia Histórico-crítica são os da concepção dialética da história, sendo assim, é tangível considerarmos como desafio teórico a questão didático-pedagógica que envolve os procedimentos metodológicos relativos ao desenvolvimento da prática de ensino em sala de aula. Portanto, analisar o material didático em seu contexto histórico é primordial para compreendermos o contexto educacional da contemporaneidade.

Consideramos essencial um debate acerca do material didático de apoio pedagógico desde a sua gênese como mediador do trabalho didático celebrando o trabalho como categoria de análise das relações sociais a fim de investigar educação e escola no âmbito das instituições de ensino no Brasil e no mundo. Sendo assim, merece atenção e uma maior visibilidade de definições do que seria material didático e também de livro didático.

O material didático pode ser definido como instrumento pedagógico utilizado em sala de aula, como mapas, jornais, murais, fotografias, dicionários, livros de gramática, livros de leitura, cadernos de exercícios. Podem ser também jornais, cartazes, encartes, embalagens de alimentos, revistas para recortes, papéis para dobraduras, calendários, sementes, entre outros. Ao entendermos material didático como tudo aquilo que pode ser usado para ampliar o conhecimento, podemos afirmar que o material didático está a serviço tanto de professores quanto dos alunos.

Existem várias definições acerca expressão livro didático: Oliveira (2004), por exemplo, define o livro didático como sendo "um material impresso, estruturado, destinado ou adequado a ser utilizado num processo de aprendizagem e de formação" (OLIVEIRA, P. 11). De acordo com Luckesi, Apud Costa (2017, p.2) "o livro didático é um meio de comunicação, através do qual o aluno recebe a mensagem escolar". Nesse sentido, o Livro Didático constituise num instrumento importante no processo de ensino e aprendizagem, desde que utilizado de forma correta, com a mediação do professor. De acordo com Bittencourt (2006), O livro didático é um depositário dos conteúdos escolares, é um instrumento que realiza uma transposição do saber acadêmico para o saber escolar no processo de explicitação curricular.

Muitas vezes o livro didático é o único material norteador do conhecimento de determinada área e/ou disciplina, no caso do ensino escolar, uma vez que não são usados como meios de promoção da aprendizagem, mas como fins em si mesmos. Sendo assim, ressaltamos a preocupação e necessidade de indagações e investigações acerca deste produto tão utilizado para o ensino na atualidade.

Entendemos que é a teoria que constitui o objeto de conhecimento e, portanto, elegemos como objeto de pesquisa, o livro didático de história para 
a escola pública por possuir importância inquestionável para o processo de ensino e aprendizagem e para o estudo histórico das relações educativas, no âmbito das instituições sociais na qual se realiza.

Considerando que, muitas vezes, o aluno da escola pública tem a escola como única forma de contato e acesso a uma cultura letrada, como único espaço de aprendizagem e de acesso ao conhecimento, e que devemos, nós, educadores, engajarmo-nos na busca pela produção e disseminação do saber sistematizado.

O aprofundamento de estudos e pesquisa sobre o processo de escolha do LD e sobre o ato de produzir pode ser compreendido como um campo que demanda estudos de diferentes abordagens científicas a fim de compreender as muitas questões ligadas ao ato de escolha do LD pois, a opção, dos professores, por uma obra ou outra pode estar ocultando ou revelando sua forma de pensar o trabalho pedagógico.

O trabalho docente impõe importantes desafios, dentre eles, a necessidade de identificar nos conteúdos, conceitos e métodos presentes no LD, que vem de encontro com o tipo de educação, escola, homem e sociedade que se pretende. Por isso, a importância de clareza, por parte do professor, da finalidade do ensino, assim ele poderá identificar a concepção teóricometodológica presente no material escolhido e fazer a mediação adequada a apropriação do conhecimento historicamente produzido pela humanidade.

Faz-se mister uma análise categórica sobre as diversas possibilidades do LD produzido e utilizado para a educação básica elucidando seus significados e intenções na busca pela compreensão das propostas educacionais na sua essência.

Com base num diagnóstico político, social e histórico, os profissionais da educação do município de Itaipulândia vêm se dedicando, desde os anos 2000, na produção e efetivação do LD para as séries iniciais do Ensino Fundamental para a escola pública, buscando a efetivação de um material de apoio pedagógico que contemple, ou que melhor se aproxime da proposta pedagógica em implementação no município, a PHC, quando busca garantir o acesso ao conhecimento científico com a finalidade de transformação social.

De acordo com Saviani (1984), o Livro didático organizado a partir da PHC deve servir como estímulo a professores e alunos no sentido de acentuar a sua capacidade criadora levando-os a descoberta e uso de novos recursos, através de sugestões múltiplas e ricas.

Partindo do pressuposto de que a educação escolar se revela como instrumento fundamental no desenvolvimento pleno do ser humano e que a função social da escola pública é a transmissão do saber sistematizado como patrimônio da humanidade, almejamos responder às seguintes questões: 
como se dá o processo histórico de construção do livro didático? Qual seu uso na atualidade? O que justifica a produção do material didático de apoio no município de Itaipulândia/PR? É possível elaborar um livro didático como produção teórico-prática revelando os pressupostos da Pedagogia Históricocrítica?

São muitas as questões subjacentes ao ato de escolher um Livro Didático para a escola pública e as respostas a estas questões podem colaborar na avaliação das políticas públicas e na capacitação de profissionais que possam estar cada vez mais habilitados para identificar as necessidades presentes, bem como, para lidar com as adversidades e a diversidade, contribuindo de maneira efetiva para a melhoria da qualidade da educação.

A intenção que move este esforço é contribuir para o difícil, mas desafiante e, ao mesmo tempo, prazeroso trabalho do professor que diariamente enfrenta salas de aula heterogêneas com estudantes cujos anseios se diferenciam ante um mundo complexo e nebuloso que se abre para eles. $\mathrm{E}$ buscar a tecitura do que compõe o real, é, sem dúvida, um caminho que pode contribuir com expectativas no resgate do professor como sujeito de transformação.

\section{ORIGEM DO OBJETO DE ESTUDO}

Compreender o processo de produção do livro didático de história utilizado nas séries iniciais do Ensino Fundamental para a escola pública, identificando as contribuições, limites e desafios da Pedagogia Histórico-Crítica no contexto educacional atual representa uma tarefa desafiadora e complexa.

Desafiadora porque se trata de um tema relevante e imprescindível para pensar a possibilidade de instrumentalizar a escola pública brasileira de modo que esteja subsidiada com material de apoio pedagógico cuja teoria direcione o ensino dos saberes científicos, culturais, artísticos e filosóficos, mediado pelo professor, que proporcione aos estudantes, um ensino de qualidade. Buscar a construção de uma escola pública democrática, inclusiva, reflexiva e competente nos remete a desafios ligados a compreensão da realidade num contexto histórico e de totalidade.

Além de desafiadora, a tarefa configura-se complexa porque exige compreender a materialidade do ensino considerando que a escola está inserida na sociedade. É pois, necessário entender o uso do livro didático nas salas de aula observando o papel do professor e a teoria pedagógica que compreende. O livro didático tem sido objeto de análise e discussão especialmente, nos últimos vinte anos, mas tratar do livro didático significa 
compreendê-lo como instrumento de ensino desde a sua gênese, nas suas múltiplas facetas.

Nesse sentido, conhecer o processo de produção do livro didático para a disciplina de história na rede pública exige que se faça o resgate do seu percurso histórico, tendo em vista que a reflexão sobre o passado esclarece o presente, assim como orienta ações possíveis para projetar o futuro. Atuando na educação básica há 20 anos, entendo que a neutralidade é impossível, que tomarmos uma posição nesta sociedade tão desigual, também é sinônimo de resistência.

Analisar o Livro Didático para a escola pública é, para mim, um desafio importante visto que, desde os primeiros passos da profissão, deparei-me com o uso constante desse recurso. Ao perceber sua presença e uma dependência, tanto dos alunos, quanto dos professores, na sua utilização para nortear as práticas de ensino na escola, também ensejei, na minha jornada docente, um livro que me ajudasse a encaminhar o ensino e aprendizagem numa perspectiva que atendesse a proposição de conteúdos e assuntos relacionados com a prática social, sendo problematizados, elaborados cientificamente e com finalidades claras, mas sempre necessitei buscar em outras fontes, consultar outras bibliografias para o trabalho em sala.

No início da minha carreira docente, mesmo com muita escassez de material de apoio pedagógico, o Livro Didático era o suporte principal nas estratégias pedagógicas da maioria dos profissionais com quem convivia. Porém, não havendo satisfação num trabalho que me parecia pragmático e sem finalidades claras passei a questionar o LD presente nas salas de aula, quanto à sua função, já que na maioria dos livros que utilizava não era necessário que o professor tivesse domínio de conteúdos, técnicas ou metodologia para desenvolver as aulas, bastava realizar a leitura dos textos e atividades para que o aluno completasse as tarefas e memorizasse o conteúdo disposto em cada parte do livro. Outro questionamento se refere a forma simplificada e fragmentada dos conteúdos a serem trabalhados, além de não terem consonância com grande parte dos conteúdos propostos no plano de ensino e/ou no currículo. Isso me deixava cada vez mais intrigada, instigando a presente pesquisa.

Considerando suas diversas formas de uso, seja para consulta, referência textual, pesquisa ou resolução de atividades, o livro didático abre múltiplas possibilidades de análise ao longo de sua utilização mas, apesar disso, percebe-se que o mesmo não perdeu seu caráter de 'apoio' pedagógico.

Com base nas leituras e na própria prática docente, tendo em vista meus anseios de pesquisadora e a importância do livro didático na sala de aula, assumimos como objeto de estudo principal "o uso do Livro Didático de apoio 
pedagógico no ensino de história para as séries iniciais do Ensino Fundamental no município de Itaipulândia/PR na perspectiva da Pedagogia HistóricoCrítica".

Além das considerações, cotidianamente, na função docente, observamos a insatisfação de professores, especialmente, com as condições materiais para o exercício da docência, com a falta de colaboração e apoio das famílias dos discentes e com os resultados obtidos através do seu ensino. Essas insatisfações se expressam na falta de entendimento acerca das leis de funcionamento da sociedade, da função social da escola, e da teoria que embasa sua prática, dentre outros.

Atualmente, com as estruturas educacionais fragilizadas vai se evidenciando cada vez mais que as contradições que marcam a organização social baseada na propriedade privada. De acordo com Saviani (2013), faz-se necessário retomar o discurso crítico que se empenha em apontar as relações entre a educação e os condicionamentos sociais, evidenciando a determinação recíproca entre a prática social e a prática educativa, entendida, ela própria, como uma modalidade específica da prática social.

A função da escola pública tem se caracterizado pelo aviltamento dos conteúdos que segue a lógica do sistema manufatureiro nas instituições de ensino, bem como pela vulgarização do conhecimento devido ao anacronismo do trabalho didático na escola, impossibilitando a ascensão dos indivíduos ao conhecimento humano culturalmente significativo. Segundo Alves (2006), um dos maiores desafios da escola pública é justamente a organização de uma nova didática na desconstrução do sistema manufatureiro instaurado nas instituições de ensino. Aceitar esse desafio implica tornar o educador cidadão, sujeito das transformações da educação e da sociedade.

Caminhar no sentido de superar os principais problemas explicitados pelos docentes da atualidade e para a produção de uma escola pública de qualidade, implica, aos professores, além do reestabelecimento de acesso ao conhecimento culturalmente significativo, conhecer a realidade existente e não esperar as condições materiais para iniciar ou dar continuidade ao processo. Na busca por um resultado satisfatório da educação como aquele saber que emerge como resultado do processo de ensino e aprendizagem, se faz necessário tomar como referência o conhecimento clássico, historicamente produzido pela humanidade.

Nesse sentido, a Pedagogia Histórico-crítica é, sem dúvida, uma teoria educacional que visa a resgatar a importância da escola e a reorganização do processo educativo, sendo a perspectiva que mais nos aproxima, discentes e docentes, de uma proposta de transformação social. Sendo assim, abordar a prática pedagógica sob a ótica do material didático tem relevância no sentido 
de identificar os pressupostos e as contribuições da teoria da Pedagogia Histórico-crítica no ensino ofertado na rede pública municipal de Itaipulândia.

Desejamos contribuir, com nossa pesquisa, principalmente no sentido de que os profissionais da educação possam compreender e vislumbrar possibilidades de ações contra-hegemônicas, e na produção de estratégias na luta contra a vulgarização e superficialização do ensino destinado a classe dominada. Pretende-se despertar nos professores, o desejo de buscarem testar em suas práticas as potencialidades da teoria cujos elementos se revelam na proposta educativa traduzida na pedagogia histórico-crítica.

São múltiplas as formas possíveis de abordagem do livro didático, seja como suporte para os conteúdos elencados nas propostas curriculares, como instrumento pedagógico, como veículo portador de ideologias, ou, ainda, na sua relação com a indústria editorial. Sendo assim, elegemos o uso do livro didático para o ensino de história para análise pois, abarcar mais áreas do conhecimento em tão pouco espaço de tempo num amplo objeto de estudo que demanda uma reflexão profunda, sistemática e contextualizada seria, a nosso ver, pretensioso demais diante das limitações de tempo. Compreendemos que cada área do conhecimento merece uma reflexão aprofundada e sistemática como importantes objetos culturais que se apresentam.

Portanto, nosso estudo centra-se na produção do livro didático de história para a educação básica na perspectiva da Pedagogia Histórico-Crítica, observando seus limites e contribuições para a educação pública da contemporaneidade. Além disso, consideramos que a linha de pesquisa, o método materialista histórico dialético e a perspectiva teórica que buscamos para o estudo se inter-relacionam, sendo um facilitador no desenvolvimento da nossa pesquisa.

\section{DIALOGANDO COM A LITERATURA}

A proposta tem como fundamentação teórica as Obras de críticos e defensores de uma sociedade que se diferencie da atual, uma sociedade que possa ser compreendida e modificada, por meio de análise numa visão de totalidade. Sendo assim, referências teóricas clássicas como Marx e Engels (2008), Gilberto Luís Alves (2005 - 2006 - 2015), Istvan Mészaros (2010), Dermeval Saviani (2002 - 2012 - 2013 - 2019), João Amós Comenius (2001) Newton Duarte (2016), Maria de Lourdes Chagas Deiró Nosella (1981), Circe Maria Bittencourt (1997 - 2018), José Claudinei Lombardi (2010) dentre outros, além das referências documentais, servirão de base para nossa pesquisa. 
Quanto às Obras citadas, $A$ ideologia Alemã (2008) revela que "toda historiografia deve partir das bases naturais e de sua transformação pela ação dos homens, no curso da história" (MARX E ENGELS, p.10), é nesta Obra que Marx estrutura a concepção materialista histórica dialética fundamentada no modo humano de produção da existência. Na Obra O Prefácio à Crítica da Economia Política (1982) pode-se destacar a luta de classes como a chave para a compreensão da sociedade, pois, sem o conhecimento da realidade em suas múltiplas determinações não seria possível pensar numa transformação social, bem como apontam as demais Obras em referência. Ambas reconhecidas por terem captado as contradições de seu tempo e terem contribuído com as necessidades históricas.

Com relação às fontes documentais, estas, nos permitem entender as normas e leis relacionadas ao nosso objeto de estudo, a saber, o Livro Didático para a escola pública. Outras fontes de apoio, propiciadas pela historiografia, deverão contribuir para nossa análise, onde entendem que o passado é o único recurso para desvelar o presente. Dentre eles, Geraldo Balduino Horn, João Carlos da Silva, Liliana Gothein, João Luis Gasparin, Ana Carolina Galvão, Bárbara Freitag, Marlene Sapelli, Eliane Viana (2016), dentre outros, devem contribuir para com a nossa pesquisa.

Marx pensou a teoria a serviço da revolução, preocupou-se em compreender a sociedade burguesa da sua época, segundo ele, "na produção social da sua vida os homens entram em determinadas relações, necessárias, independentes da sua vontade, relações de produção que correspondem a uma determinada etapa de desenvolvimento das suas forças produtivas materiais" (MARX, 1982, p.2). Marx parte das condições de reprodução da vida social e das relações estabelecidas entre os homens, destaca ainda, que a consciência se desenvolve em determinadas condições históricas, a partir das contradições da vida material, do conflito presente nas forças produtivas e das relações de produção sociais.

Compreender o materialismo histórico é primordial para desenvolvermos uma pesquisa na linha dialética, tendo explícita a ideia de que existe uma realidade objetiva fora da consciência, que é o aspecto derivado da matéria. Para tanto, faremos uma reflexão acerca da teoria marxista buscando nos clássicos, os pressupostos teóricos metodológicos.

Mészaros (2010), em "A educação para além do capital” pressupõe que "apenas a mais ampla das concepções de educação nos pode ajudar a perseguir o objetivo de uma mudança verdadeiramente radical, proporcionando elementos de pressão que rompam com a lógica mistificadora do capital" (MÉSZAROS, 2010, p.48) assim, entendemos que a educação formal institucionalizada pode ser propulsora de mudanças ou, ainda, mantenedora 
da ordem existente o que implica dizer que é a consciência do agente educacional (o professor) como mediador do processo de formação dos indivíduos para a transformação social que poderá contribuir para o desenvolvimento humano pleno.

De fato, o papel dos professores tem suma importância e grande responsabilidade e deve se dar de forma coletiva, ativa e dinâmica, num processo de "totalidade das práticas político-educacional-culturais, na mais ampla concepção do que seja uma transformação emancipadora" (MÉSZAROS, 2010, p.57).

Ao tratar da educação formal, buscamos em Dermeval Saviani, o propósito de elevar a prática educativa dos educadores do nível do senso comum ao nível da consciência filosófica. Segundo Saviani (1996), "a passagem do senso comum à consciência filosófica é condição necessária para situar a educação numa perspectiva revolucionária [...], preocupar-se com a educação significa preocupar-se com a elevação do nível cultural das massas" (SAVIANI, p. 5). Isso significa que o professor necessita adotar uma teoria centrada na transmissão do conhecimento artístico, filosófico e científico, produzido historicamente pela humanidade.

Ainda nas obras de Saviani, abordamos a Pedagogia Histórico-Crítica (PHC) como base para os nossos estudos pela concepção de educação explicitada como "o ato de produzir, direta e intencionalmente, em cada indivíduo singular, a humanidade que é produzida histórica e coletivamente pelo conjunto dos homens" (SAVIANI, 2013, p.13).

De acordo com Silva (2018), "a PHC visa a alcançar os interesses da classe trabalhadora no sentido da valorização da escola pública, do professor e do conteúdo como patrimônio histórico da humanidade" (p.24). Sendo assim, a referida teoria deve superar o desafio de sua implantação na prática docente no enfrentamento desta sociedade regida pelo capital.

Segundo Saviani (2013), a escola tem o papel de possibilitar o acesso das novas gerações ao mundo do saber sistematizado, do saber metódico, científico." O autor afirma ainda, que os defensores da referida proposta pedagógica desejam a transformação da sociedade, ou seja, do ponto de vista pedagógico, trata-se de socializar o saber elaborado. $\mathrm{O}$ que vem de encontro com nosso objeto de estudo quando almejamos a implementação de uma proposta pedagógica que se aproxime de um processo de transformação social.

De acordo com Saviani (1996) "toda relação de hegemonia é necessariamente uma relação pedagógica", o que imprime uma compreensão de que a educação é um instrumento de luta cujo papel se dá na elevação do 
nível cultural das massas, tornando o proletariado erigido em força hegemônica. (SAVIANI, p.3).

Ao buscarmos fundamentação a partir dos clássicos, explicitamos que o conceito de clássico por Saviani vem de encontro com a expectativa de nossa procura. Segundo ele, "o clássico não se confunde com o tradicional e também não se opõe, necessariamente, ao moderno e muito menos ao atual. Clássico é aquilo que se firmou como fundamental, como essencial (SAVIANI, 2013, p. 13)."

Comênius é um clássico, ao mostrar as leituras originais que fizera do seu tempo nos ajudando a entender quem somos e aonde chegamos, especialmente na questão referente ao modelo de ensino e ao Livro Didático utilizado na educação básica no Brasil, bem como, nas palavras de Gasparin (1997, p. 39), "propicia-nos a sensibilidade e o incitamento para uma leitura adequada de suas ideias diante da realidade atual".

Conforme Gasparin (1997, p.62) a concepção comeniana de homem é uma expressão de determinações estruturais, de determinações e valores, do avanço das ciências naturais e das filosofias presentes no século XVII.

Comênius acreditava numa escola para todos, na sua reforma, na existência de escolas por todos os lugares e no método adequado para que o ensino acontecesse com a finalidade de produzir homens sábios na mente, prudentes nas ações e piedosos no coração. Delegou ao educador, a incumbência de imitar, em sua ação educadora, o artesão, que domina sua arte. Requer-se um professor universal, com características como prudência, piedade, trabalho, honestidade e dignidade, que devem ser produzidas em seus educandos. Ao educador, cabe unir o processo espontâneo da natureza a ação direta e intencional da educação. A obra comeniana harmoniza teoria e ação e sugere os livros clássicos para o ensino.

Segundo Comenius: "A arte de ensinar nada mais exige, portanto, que uma habilidosa repartição do tempo, das matérias e do método" (COMENIUS, 2001, P. 190). O Teólogo propôs uma instrução verdadeira e sólida, em que o homem fosse capaz de subtrair o conhecimento genuíno e (de) utilidade. Uma formação suave em menor tempo e com menor esforço.

Mas Comênius, ao introduzir os livros no mundo educacional, nos alerta que, mesmo que sejam lidos, entendidos e memorizados, eles não são suficientes para que se transformem em ações, ou seja, não são suficientes para a formação do homem, necessitando do professor como formador de todos os homens na sua trilogia: instrução, moral e religião.

No que tange à escola pública, Gilberto Luís Alves traz importantes contribuições quando propõe a produção de uma nova instituição educacional no que se refere ao trabalho didático, à produção de instrumentos de trabalho 
que incorporem novas tecnologias, e à constituição de um novo profissional da educação para a contemporaneidade.

De acordo com Mészáros (2008), a nossa tarefa educacional é, simultaneamente, a tarefa de uma transformação social ampla e emancipadora. Assim, entendemos que, enquanto educadores, quanto mais nos apropriamos dos conhecimentos e da cultura historicamente produzidos pela humanidade, mais aptos estamos a forjar uma escola para a emancipação humana.

Neste sentido o desafio é articular teoria e prática em consonância com uma pedagogia que leve o aluno a um conhecimento verdadeiro que the possibilite a apropriação do conhecimento acumulado pela humanidade e, assim, possa participar das lutas de seu tempo e contribuir para a transformação da sociedade. E isto só será possível se o saber escolar lhes fornecer elementos para uma ruptura com a ideologia dominante, o que nos leva a constatar que a Pedagogia Histórico-Crítica traduz com eficiência estes objetivos. Sabemos que a escola, inserida nesta sociedade capitalista, é também palco da luta de classes, e portanto, necessita de uma teoria pedagógica contra-hegemônica no sentido de alcançar uma educação essencial que defenda os interesses da classe trabalhadora.

Segundo Viana (2016), a PHC defende e luta por uma escola que realmente contribua para a formação de um ser humano que compreenda a estrutura da sociedade e possa se desenvolver em patamares superiores, para que, instrumentalizado, lute coletivamente, para a construção de uma nova humanidade (VIANA, 2016, p.41). Afirma ainda, em sua pesquisa, que "é preciso criar mecanismos para desenvolver e possibilitar a compreensão do mundo à luz do Materialismo Histórico Dialético e, com isso, o senso de coletividade, a consciência de classe." (VIANA, 2016, p. 129).

Ademais, é primordial assumirmos um real compromisso com o presente, buscando no passado, elementos que desvelem e tornem inteligível o processo de produção da escola pública brasileira. Em tempos obscuros, fiquemos alertas, resistência e luta da e para a classe trabalhadora, através da socialização do conhecimento produzido coletivamente pela humanidade.

\section{CONSIDERAÇÕES FINAIS}

A revisão bibliográfica sobre o livro didático no Brasil bem como da discussão acerca do ensino de história e da perspectiva teórica na qual propomos esse estudo, nos leva a algumas constatações que permitem a compreensão do livro didático como ferramenta pedagógica que pode contribuir para a (trans)formação social. 
O ensino sempre esteve vinculado de alguma forma, a um livro escolar. Instrumento responsável pela formação de gerações, o livro didático ainda é o principal recurso utilizado não só como ferramenta didático-pedagógica, mas como fonte de consulta pessoal. O livro didático tem sido o principal responsável pela concretização dos conteúdos históricos escolares. Cabe ao professor analisar a forma como esses conteúdos são apresentados e buscar outras fontes bibliográficas e documentais a fim de apresentar os conceitos e informações de forma precisa, considerando as características dos estudantes.

A recepção e utilização dos didáticos nas instituições de ensino é diversa, até porque o público escolar é constituído de características distintas, heterogêneas. Independentemente da sua forma de uso, seja como único material ou de uso eventual, o professor deve ser o mediador entre o livro didático e o estudante, realizando constantes intervenções.

É necessário considerar e emergência do atual estágio de desenvolvimento da sociedade brasileira, em que as atividades práticas incorporam cada vez mais ciência e tecnologia. Há que se voltar para uma nova concepção de ensino de história, com uma metodologia capaz de melhor apreender o movimento do real, e sua transformação na perspectiva defendida pela Pedagogia Histórico-crítica.

Partindo da concepção de que o conhecimento histórico é produzido socialmente e que o professor, sujeito constituído nesta sociedade, muitas vezes não consegue passar do senso comum devido aos diversos fatores que envolvem desde a sua formação a sua atuação, em que o professor acaba usando apenas o livro didático, levando o aluno a acreditar que esta é a única fonte digna de confiança. Esse alerta levou os educadores de Itaipulândia a se mobilizarem na construção de um livro didático para a rede pública municipal de ensino.

O Livro Didático de apoio pedagógico produzido para estudantes da rede municipal de ensino de Itaipulândia, foi pensado na perspectiva teórica da PHC, tendo como pressuposto filosófico o Materialismo Histórico Dialético, e como fundamento psicológico, se apoia na psicologia histórico-cultural.

O livro didático tem se constituído como uma fonte importante de mediação pedagógica, desde a sua gênese. E são as situações cotidianas que despertam essa discussão pois, é na observância e no diálogo com os agentes do processo de ensino e aprendizagem, os professores, que se revelam as questões que motivam este debate.

Cabe pois, olhar criticamente o passado e indagar acerca de qual das versões da história, interpretada de forma antagônica pelas diversas ideologias, está sendo ensinada às novas gerações. Compreender sob qual perspectiva teórica, analítica, histórica e qual a postura do professor que 
também é resultado de um processo histórico, com acesso a algum tipo de conhecimento, está se ensinando. É preciso oferecer uma instrução capaz de tornar os indivíduos críticos, sensatos, providos de saberes que propiciem a compreensão da realidade social, voltado para transformações sociais profundas.

\section{REFERÊNCIAS}

ALVES, Gilberto Luiz. A produção da escola pública contemporânea. Campinas, SP: Autores Associados, 2006.

ALVES, Gilberto Luiz. 0 trabalho didático na escola moderna: formas históricas - Campinas, SP: Autores Associados, 2005. - (coleção educação contemporânea)

ALVES, Gilberto Luiz. (Org.) Textos escolares no Brasil - clássicos, compêndios e manuais didáticos. Campinas/SP. Autores Associados, 2015. (coleção memória da educação).

AZEVEDO, E. M. Livro didático: uma abordagem histórica e reflexões a respeito de seu uso em sala de aula. Mestrando em História pela Universidade Federal de Uberlândia. Disponível em:

http://www.fucamp.edu.br/wp-content/uploads/2010/10/7.Ede \%23U00c3\%23U00adlson-Matias-de-Azevedo.pdf. Acesso em 27 abr. 2019.

BRASIL. MEC/SEF. Guia de Livros Didáticos 2005/ História. Brasília: Ministério da Educação. SEF. 2019.Disponível em: http://portal.mec.gov.br/secretariade-educacao-basica/publicacoes/195-secretarias-112877938/seb-educacaobasica-2007048997/12637-guias-do-programa-nacional-do-livro-didatico. Acesso em 12 maio 2019.

BALZAN, C. S. Os desafios da implementação da Pedagogia Histórico-Crítica nos anos iniciais do Ensino Fundamental em Itaipulândia-Paraná. Cascavel, 2014, Dissertação (Mestrado em Educação) Universidade Estadual do Oeste do Paraná, 2014.

BITTENCOURT, C. M. Livros didáticos: concepções e uso. Recife: Secretaria da Educação e Esporte de Pernambuco, 1997. (Coleção Qualidade do Ensino, Série: Formação do Professor).

BITTENCOURT, Circe. 0 saber histórico na sala de aula. 11. ed. São Paulo: Contexto, 2006. 
BORGES, Bruno Gonçalves. JÚNIOR, Décio Gatti. O ensino de história da educação na formação de professores no Brasil atual. Revista HISTEDBR Online. Disponível em:

http://www.histedbr.fe.unicamp.br/revista/edicoes/40/art02_40.pdf Acesso em: 20 set. 2019.

CASSIANO, Célia Cristina de Figueiredo. O mercado do livro didático no Brasil no século XXI. 1ạ ed. São Pulo. Editora Unesp. 2013.

CARVALHO NETO, Eulália Raquel Gusmão de. O livro didático e as teorias pedagógicas. Artigo submetido em novembro/2014 e aceito em novembro/2015 DOI: 10.15628/holos.2015.2602. HOLOS, Ano 31, Vol. 6. Disponível em: https://www.researchgate.net/publication/286636534. Acesso em: 16 abr. 2019.

COMENIUS, João Amós. Didática Magna. Versão digitalizada - e-book. Introdução, tradução e notas: Joaquim Ferreira Gomes. 2001.

COSTA, Maria Helena de Carvalho. MACENA, Romildo Araújo. CRISPIM, Rafael Cândido. NETO, Olívio Medeiros de Oliveira. SANTOS, José Ozildo dos. O papel do livro didático no processo educativo. In: IVCONEDU-IV Congresso Nacional De Educação. Anais Eletrônicos... Disponível em:

http://www.editorarealize.com.br/revistas/conedu/trabalhos/TRABALHO_EVO 73_MD1_SA2_ID7225_26092017152510.pdf. Acesso em: 20 jul. 2019.

CURRICULO DA AMOP. Currículo Básico para a escola pública municipal região oeste do Paraná: Educação Infantil e ensino Fundamental. 2019.

DUARTE, Newton. Os conteúdos escolares e a ressurreição dos mortos: contribuição à teoria histórico-crítica do currículo/Newton Duarte. Campinas, sp. Autores associados, 2016. - (coleção educação contemporânea).

FRANCO, Maria Laura P. B. O Livro Didático de História no Brasil. São Paulo. Global Editora, 1982.

FREITAG, Bárbara. COSTA, Wanderly F. da. MOTTA, Valéria R. O Livro Didático em questão. São Paulo. Cortez: Autores Associados. 1989. (Coleção educação contemporânea).

GALVÃO, Ana Carolina. LAVOURA, Tiago Nicola. MARTINS, Ligia Márcia. Fundamentos da didática histórico-crítica. 1a edição. Campinas/SP. Autores Associados, 2019.

GASPARIN, João Luís. Comênio - a emergência da modernidade na educação. Vozes. Petrópolis/RJ. 1997. 
GUIMARÃES, Lucia Maria Paschoal. LEONZO, Nanci. A Reforma de Base no Ensino da História Pátria: o projeto da História Nova do Brasil. / Revista de História 149 (2 - 2003), p. 225-235

GOTHEIN, Liliana. A gênese da composição de um material didático para ensino-aprendizagem de português como segunda língua. 2007, Tese (doutorado em Linguística Aplicada) Universidade Estadual de Campinas, Instituto de estudos da linguagem. Campinas, 2007

MATOS, Neide da Silveira Duarte de. SOUSA, Joceli de Fátima Arruda. SILVA, João Carlos da. (org.). Pedagogia Histórico-crítica: revolução e formação de professores. Campinas, SP: Armazém do Ipê, 2018.

MARSIGLIA. Ana Carolina Galvão. A Prática Pedagógica Histórico-Crítica na educação infantil e ensino fundamental. Campinas - SP. Autores Associados (coleção educação contemporânea). 2011.

MARX, Karl. A Ideologia Alemã. Karl Marx e Friederich Engels; tradução Luís Claudio de Castro e Costa. - 3a Ed. - São Paulo: Martins Fontes, 2007.

MARX, Karl. Para a Crítica da Economia Política. Janeiro de 1859 Obras Escolhidas em três tomos, Editorial "Avante!". Tradução: José BARATA-MOURA (Publicado segundo o texto do livro. Traduzido do alemão). Transcrição e HTML: Fernando A. S. Araújo, março 2007. Edições Progresso Lisboa Moscovo, 1982. Disponível em:

https://www.marxists.org/portugues/marx/1859/01/prefacio.htm. Acesso em: 10 ago. 2019.

MÉSZÁROS, I. A educação para além do capital. Tradução Iva Tavares. São Paulo: Boitempo, 2008.

MORETTO, Milena- org. OLIVEIRA, Patrícia de. O Livro Didático na Educação Básica: múltiplos olhares. Jundiaí. Paco Editorial, 2017.

NOSELLA, Maria de Lourdes chagas Deiró. As Belas Mentiras: a ideologia subjacente aos textos didáticos.8 ed. São Paulo. 1981.

PAGNONCELLI, Cláudia. MALANCHEN, Julia. MATOS, Neide da Silveira Duarte de. (orgs.) $\mathbf{O}$ trabalho pedagógico nas disciplinas escolares - contribuições a partir dos fundamentos da Pedagogia Histórico-Crítica. Campinas, SP, 2016.

PANIAGO, Maria Lucia. "Livro Didático" a simplificação e a vulgarização do conhecimento. 1a edição. São Paulo - Instituto Luckács, 2013. 
RANGEL, Mary. Qualidade do livro didático: dois critérios da literatura acadêmica do programa nacional do livro didático. Linhas Críticas [online]. $\mathrm{n}$. 11, 2005. Disponível em: http://www.redalyc.org/articulo.oa? id=193517360001 ISSN 1516 -4896. Acesso em 25 maio 2019

RIBEIRO, Maria Luisa Santos. História da educação Brasileira - a organização escolar. 21a edição. 1a reimpressão. Campinas, SP. Autores Associados. HISTEDBR, 2011. (Coleção memória da educação).

RODRIGUES, José Roberto Gomes. Pedagogia e ensino de história da educação. Brasília, DF. Líber Livro. 2012.

SAVIANI, D. Pedagogia Histórico-Crítica: primeiras aproximações. Campinas, SP: Autores Associados, 2013 (Coleção educação contemporânea).

VALDEMARIN, Vera Teresa. Estudando as lições de coisas: análise dos fundamentos filosóficos do Método de Ensino Intuitivo. Campinas/SP. Autores Associados. 2004. (coleção educação contemporânea)

VIANA, E. A Pedagogia Histórico-Crítica na rede municipal de educação de Itaipulândia/PR (2004-2016) 2017, Dissertação (Mestrado em Educação) Cascavel: Universidade Estadual do Oeste do Paraná, 2017.

VILAÇA, M. L. C. O material didático no ensino de língua estrangeira: definições, modalidades papéis. Revista Eletrônica do Instituto de Humanidades da Unigranrio. Volume VII. Número XXX. Julho-Setembro de 2009. Disponível em:

http://publicacoes.unigranrio.edu.br/index.php/reihm/article/view/653/538. Acesso em: 10 maio 2019. 